\title{
Professionally-Oriented Linguvodidactics: Formation of Research Competence of Students Who Learn Russian
}

\section{Pakhalkova-Soich Tetiana Vladimirovna ${ }^{1}$}

Associate Professor, Kharkiv National University of Radio Electronics, Kharkiv, Ukraine.

\section{Morozova Lana Jur'evna ${ }^{2}$}

Associate Professor, Kharkiv National University of Radio Electronics, Kharkiv, Ukraine.

(date of receiving: April, 2019; date of acceptance: September, 2019)

\begin{abstract}
Modern trends in the educational paradigm cause increased attention to the professional training of students. The acquisition of professional knowledge depends on the knowledge of the language of the specialty for students. Training provides for a focus on the content of educational material and on activities that are made up of techniques and operations that form professional skills. The effectiveness of training depends on the correct choice of principles, approaches, methods, receptions and ways of teaching, the pedagogical conditions of professionally oriented learning to have been determined. The main topics and corresponding typical communicative situations are singled out, on the basis of the analysis of the professional speech of engineers. Teaching professionally oriented dialogical speaking of foreign students of engineering specialties of higher educational institutions can be presented as a linguodidactic model. Linguodidactic model formed on the basis of modern requirements for vocational training. It reflects the purpose and content of education, outlines the pedagogical conditions of the formation process and the final result - the formation of professionally oriented dialogical speech in students.
\end{abstract}

Keywords: Communicative Competence, Professionally Oriented Linguodidactics, Situationality, Creative Self-Expression, Professional Aspect.

1. E-mail: p-soich@rambler.ru

2. E-mail: lanmoroz@rambler.ru 


\title{
Профессионально-ориентированная лингводидактика: формирование исследовательской компетенции студентов, изучающих русский язык
}

\author{
Пахалкова-Соич Татьяна Владимировна ${ }^{1}$
}

Доцент, Харьковский национальный университет радиоэлектроники, Харьков, Украина.

\section{Морозова Лана Юрьевна 2 \\ Доцент, Харьковский национальный университет радиоэлектроники,} Харьков, Украина.

(дата получения: апрель 2019 г.; дата принятия: сентябрь 2019 г.)

\begin{abstract}
Аннотация
Современные тенденции образовательной парадигмы обусловливают повышенное внимание к профессиональной подготовке студентов, для которых получение профессиональных знаний зависит от владения языком специальности. Обучение предусматривает направленность на содержание учебного материала и на деятельность, которая складывается из приемов и операций, формирующих профессиональные умения. Результативность обучения зависит от правильного выбора принципов, подходов, методов, приемов и способов обучения, благодаря которым были определены педагогические условия профессионально ориентированного обучения. На основе анализа профессиональной речи инженеров выделяют основные темы и соответствующие им типовые коммуникативные ситуации. Обучение профессионально ориентированному диалогическому говорению иностранных студентов инженерных специальностей высших учебных заведений можно преподнести в виде лингводидактической модели, образованной на основе современных требований к профессиональной подготовке, которая отображает цель и содержание образования, очерчивает педагогические условия процесса формирования и конечный результат - сформированность профессионально ориентированной диалогической речи у студентов.
\end{abstract}

Ключевые слова: Коммуникативная Компетенция, ПрофессиональноОриентированная Лингводидактика, Ситуативность, Творческое Самовыражение, Профессиональный Аспект.

1. E-mail: p-soich@rambler.ru

2. E-mail: lanmoroz@rambler.ru 


\section{Введение}

В условиях расширения международного сотрудничества учет специфики профессии приобрел приоритетное значение в обучении иностранному языку. Иноязычное общение становится существенным компонентом профессиональной деятельности специалистов.

Изучение русского языка становиться не самоцелью, а средством достижения цели - повышения уровня образованности, эрудиции в рамках своей специальности. Учет специфики профилирующих специальностей, по нашему убеждению, должен осуществляться по таким направлениям: работа со специальными текстами, изучение специальных тем для развития устного высказывания, создания грамматических и лексических материалов для активизации уровня владения научным стилем речи студентов (Образцов 2005. 61). Материал, необходимый для изучения иностранного языка, должен отвечать следующим требованиям: актуальность содержания, информативность, конкретная тематика общения, мотивированность профессиональной деятельностью студента. Важно использовать аутентичные источники научно-популярной литературы, периодические издания последних лет, Интернет.

Проблема оптимизации обучения профессиональной речи иностранных студентов инженерно-технических вузов представлена различными аспектами: исследованиями в языковой компетенции, определением качества устного высказывания и др.

Целью профессионально ориентированного обучения является формирование коммуникативной компетенции иностранных студентов, а именно, владение нормами современного русского языка, терминологией, вербальными и невербальными способами общения, культурой профессионального говорения. Профессионально ориентированное обучение 
предусматривает направленность, как на содержание учебного материала, так и на деятельность, складывающуюся из приемов и операций, которые формируют профессиональные умения. Результативность обучения зависит от правильного выбора принципов, подходов, методов, приемов и способов обучения.

В основу системы обучения легли общие принципы - научность, системность, последовательность и перспективность, доступность, связь теории с практикой, активность, самостоятельность и специальные принципы - ситуативность, профессионально-коммуникативная направленность (Дроздова 2009. 56-62). Следуя этим принципам, были определены педагогические условия профессионально ориентированного обучения. Такие виды учебной деятельности, которые максимально активизируют студентов, способствуют их творческому самовыражению (дискуссии, презентации, конференции, проектная работа и пр.) (Пахалкова-Соич 2016. 174).

Важным аспектом для активизации обучения является создание условий для самостоятельной познавательной деятельности студентов, формирование познавательных умений для индивидуально-творческой деятельности. При этом со студентом осуществляется индивидуально-дифференцированная работа.

\section{Основная часть}

Изучение иностранного языка - это активный процесс, в качестве основы которого выступает умение применять иностранный язык в нужной ситуации.

Важной составляющей научно-исследовательской работы студентов, их подготовки к будущей профессиональной деятельности являются научнопрактические конференции.

Задачами конференции являются: привлечение студентов к поисковоисследовательской работе и решению проблем, которые имеют практическое 
значение для развития науки, культуры; формирование у студентов навыков самостоятельной работы по изучению дисциплин, не входящих в учебные планы и программы; повышение качества подготовки специалистов за счет творческого подхода к усвоению студентами дополнительного учебного материала; стимулирование заинтересованности молодежи к актуальным проблемам современности; создание условий для реализации инновационного потенциала молодежи; формирование творческих связей и расширения международных отношений.

Студент должен уметь работать с научно-техническим текстом, а для этого необходимо знать особенности письменной и устной форм научного стиля, а значит знать нормы и правила невербальной коммуникации профессионального общения и владеть нормами построения и языкового оформления научных текстов. Студент должен уметь подготовить и провести публичное выступление, научную беседу или дискуссию.

Обучение иностранному языку в нелингвистическом высшем учебном заведении предусматривает широкое использование иноязычной литературы по специальности. Работа с профессиональными текстами способствует как реализации учебных целей в плане овладения иностранным языком, так и решению других заданий, а именно: знакомство с публикациями по определенной профессиональной тематике, выявление новых тенденций зарубежных исследований в этой отрасли, поиск и отбор материала для научной работы и практической деятельности. Среди эффективных приемов работы с текстами по специальности важное место занимает подготовка доклада для выступления, поскольку она предусматривает, кроме сугубо чтения и перевода, еще и анализ содержания прочитанного для исключения значимой информации и синтеза этой информации в процессе создания вторичной компрессии текста. Создавая такой текст, студенты приобретают навыки самостоятельного исключения, обработки и трансформации 
информации. Однако, следует признать, что сжатое обобщение информации является непростым заданием для студентов и требует соответствующих умений и навыков.

Написанию статьи предшествует работа с научными источниками. Умение переработать первичные документы, то есть документы, несущие информацию, является одной из важнейших составных частей информационной деятельности. Для этого студентам необходимо овладеть разными приемами языкового выражения, такими как, во-первых, лексическое свертывание, которое состоит в замене словосочетания словом. Во-вторых, синтаксическое свертывание, часто сопровождаемое лексической заменой. Компрессия в плане содержания широко применяется, причем преобразование текста идет через обобщение частных фактов, то есть носит характер синтеза. В-третьих, существует также вид компрессии, называемый свертыванием промежуточных операций. Научный текст (устный или письменный) адресован узкому кругу специалистов и рассчитан на наличие общего опыта, знаний, интересов и целей. Поскольку коммуникация в науке есть непрерывный процесс, отправитель сообщения описывает не все детали денотативной ситуации, а лишь новую о ней информацию, и выявляет связи этого нового с уже известным. То, что пропущено, но относится к делу, должно восприниматься слушателем за счет собственных знаний. Вчетвертых, еще один вид компрессии называется опусканием и состоит в опускании деталей (Смирнова 1978. 156).

При подготовке доклада студенты используют различные печатные источники и статьи из сети Интернет. Преподаватель дает студентам список выражений, необходимых для языкового оформления доклада. В процессе обучения необходимо показать студентам, как суммируется текст, научить их выделять главное и оформлять свои мысли, используя предлагаемые связки. Написание доклада сложный процесс, осуществляя который необходимо 
обеспечить максимальную полноту существенной информации при минимальном объёме доклада; соответствие свёрнутой информации доклада информации первоисточника; возможность дальнейшего поиска информации.

Следует отметить, что процесс свёртывания в немалой степени определяется видом первичного документа (монография, теоретическая или обзорная статья), языком, на котором он опубликован, стилем изложения. Большое внимание уделяется основным требованиям, предъявляемым к докладу, среди которых в первую очередь нужно отметить: доклад как информационный документ, который, раскрывая содержание работы, обращает внимание на новую информацию, содержащуюся в первоисточнике; содержание работы излагается объективно; докладу присуща характерная форма изложения, отличающаяся строгой последовательностью, постоянством структуры, предельным лаконизмом (Клейменова 1982. 160). Доклад состоит из заголовочной части, основной части и справочного аппарата.

Важное значение при подготовке к выступлению на конференции приобретают самостоятельность, оригинальность высказанных мнений, умение обосновать, опровергать заблуждения. Выступление с докладом о результатах научного поиска позволяет приобрести и определенное общественное признание среди других студентов, преподавателей, а это важно для будущего специалиста.

Подготовка письменного текста доклада на конференцию должна иметь четкую логическую структуру. Необходимо у студентов формировать способность к общению на русском языке, что предполагает формирование качеств, делающих эффективным процесс овладения языком как средством межкультурной коммуникации. А именно, интерес и положительное отношение к изучаемому языку, к культуре народа, говорящего на этом языке, общечеловеческое сознание, самостоятельность в определенных видах деятельности, понимание важности изучения русского языка. 
Большое значение придается коммуникативному обучению, то есть подготовке студентов к иноязычному общению в условиях иноязычной коммуникации.

Для совместного определения преподавателем и студентом предполагаемого направления и формулировки тематики выступления предлагаются следующие критерии: актуальность проблемы, практическая направленность, наличие и доступность информации, профессиональные интересы студента, отражение полученного им практического опыта в научноисследовательской работе и в профессиональной деятельности, интерес к теме доклада.

Для подготовки выступления с докладом на конференции определены следующие временные и содержательные требования: на выступление студента по конкретной теме на основе самостоятельно собранной информации отводится 5-10 минут; в содержании доклада должна быть обоснована актуальность проблемы, сформулирована главная тема и высказано отношение докладчика к излагаемому материалу, аргументированы собственные мнение и выводы.

Этап подготовки к студенческой конференции на русском языке проводится в форме общего обсуждения под руководством преподавателя, который помогает выбрать тему доклада, консультирует, помогает студенту делать обобщения и сопоставления материалов по теме сообщения. Студенты осваивают приемы поискового чтения, аудирования, перефразирования, обработки текста, способы сокращения и структурирования информации.

Собирая материал по теме доклада, студенты по ключевым словам проводят поиск в Интернете. О результатах первичного поиска материала для доклада по выбранной теме студент сообщает преподавателю-руководителю, предъявляя статьи и заметки, сайты Интернета, аудио- и видеоматериалы по выбранной теме на русском и на иностранных языках, которыми владеет студент. 
В перечень упражнений, выполняемых на стадии объединения нового материала со старым, выполняются следующие виды коммуникативных упражнений: ситуативные, побуждающие учащихся к построению высказываний по собственной программе в определенной ситуации общения с использованием изучаемого лексико-грамматического материала. Упражнения такого типа необходимы, и для того, чтобы коммуникативно-деятельный подход не превратился в механическое использование готовых речевых образцов в готовых ситуациях, и для того, чтобы эти упражнения являлись переходом к речевым упражнениям, направленным на формирование речевых умений; коммуникативные, помогающие формированию в сознании учащихся функционально-грамматических обобщений. Эти упражнения позволяют учащимся осознать место проблемы доклада в системе аналогичных; коммуникативные, которые способствуют предотвращению ошибок, появляющихся у учащихся вследствие возможной интерференции.

Сообщение на студенческой конференции должно содержать материалы научного характера и вместе с тем должно быть понятно неспециалисту. Кроме того, желательно, чтобы студент при подготовке к выступлению на конференции заранее продумывал, какие вопросы ему могут быть заданы по теме его выступления и готовился ответить на них.

По мере необходимости студент во внеаудиторное время обсуждает с преподавателем содержание, способы оформления и презентации доклада.

При подготовке к докладу используются речевые ситуации, тренировочные упражнения и вербально-зрительные опоры, которые имитируют ситуацию «Выступление на конференции». Поэтому преподаватель использует различные виды монологической речи, ролевые игры, а также создание системы ситуативных упражнений для эффективного формирования и совершенствования навыков устной речи. 
Здесь выполняются следующие задачи: формируется у студентов мотивация к изучению русского языка, вырабатываются практические умения и навыки говорения в различных сферах общения, формируется коммуникативная компетенция, речевая культура, развиваются творческие способности, вырабатывается культура полемики, критическое мышление, анализ изученного, гуманистическое мировоззрение.

При подготовке иностранных студентов к докладу необходимо: подобрать материал по научной теме на русском и родном языке и перевести его на русский язык; обработать материал на русском языке и отредактировать его с научным руководителем; сформировать собственное мнение о прочитанном, подготовить выступление (обсудив его с научным руководителем и с преподавателем русского языка) и презентацию на русском языке (если необходимо - раздаточный материал). В ходе подготовке к выступлению иностранный студент должен изучать как минимум пятнадцать-двадцать новых слов, каждый день, усваивать незнакомые выражения.

Кроме того, большое внимание следует уделить обработке специальных клише, характерных для научного стиля и выступления. В научной речи есть целый ряд таких стереотипов, которые облегчают процесс коммуникации, экономят усилия, энергию и время докладчика.

Классификация речевых клише строится на понятийной основе, в данном случае это структура работы, например: общая характеристика работы; задачи, которые ставит автор; оценка полученных результатов исследования; подведение итогов, выводы по работе.

После подготовки текста возникает необходимость создания презентации к выступлению. Это важная творческая и сложная работа в ходе процесса обучения, поскольку она предполагает не только трансформацию текста оригинала, но и одновременное использование нескольких информационных 
сред: текста, графики, фотографий, видеоматериалов, анимации, звукового сопровождения, и пр. Кроме предметных компетенций, презентация способствует формированию рациональных приемов мышления и повышению информационной культуры.

Здесь необходимо выполнить семантические операции по преобразованию текста связаны с целым комплексом операций, таких как сравнение, анализ, синтез, обобщение, абстракция и конкретизация. Реконструкция текста распадается на следующие операции: а) исключение материала, б) цитирование, в) перемещение отдельных отрезков, г) дополнение, д) сгущение или сжатие того, что в подлиннике детализировано, е) замена одного содержания другим, равнозначным по смыслу (Вейзе 1985. 51-52).

Ситуация понимания обусловливает возможность компрессии, а значит, возможность успешно создать презентацию. «Понимание текста при чтении включает две последовательные ступени: ступень языкового понимания и ступень извлечения смысла» (Вейзе 1985. 52). Цель текстовой компрессии кратко изложить основное содержание, основную идею текста-оригинала.

Конференция помогает формировать навыки говорения через систему использования различных методов и форм обучения на уроках русского языка. Применение на практике различных методов и форм обучения при формировании навыков говорения, предоставляет возможность преподавателю повысить эффективность учебного процесса и уровень знаний студентов, а также направить учебно-воспитательный процесс на взаимопонимание, взаимодействие, решение проблем, важных для каждого из участников учебного процесса.

Участие студентов в конференции является показателем высокого уровня овладения учащимися русским языком как средством общения, приобретение учащимися навыков разговорного русского языка и умений практически их использовать в соответствии с ситуацией общения. 
Выступление с докладом (говорение) - это сложный процесс, который тесно связан с формированием и совершенствованием лексикограмматических навыков, умением использовать их для развития неподготовленной речи. В этом процессе выделяем:

- формирования монологических умений. На этом этапе нужно использовать речевые упражнения, направленные на использование средств межфразовой связи, характерных для определенного типа монолога (доклада);

- построение микромонолога. Обучение монологической речи осуществляется с помощью различных опор: изобразительных (таблицы, фотографии, диаграммы, схемы и др.), вербальных, комбинированных. При этом речь студентов не детерминируется, а лишь направляется и мотивируется коммуникативными задачами;

- обучение студентов создавать монологические высказывания текстового уровня различных типов речи в необходимом объеме (текст доклада). Для этого необходимо развитие умений выражать свое личное отношение к фактам или событиям, формулировать критическую оценку и доказывать правильность собственного мнения, включать в свою речь элементы рассуждения, аргументации. Студенты должны заранее усвоить ряд словосочетаний и штампов, характерных для монологической речи.

Важным педагогическим условием эффективного обучения иностранных студентов является информационно-методическое сопровождение, которое обеспечивают учебные планы и программы, методические рекомендации к ним, научные пособия, информационно-справочные и другие учебнометодические материалы, комплексы различных форм учебных занятий, технические средства обучения, дидактические материалы к ним.

Эффективность обучения зависит от отбора методов и приемов, подходов, использования педагогических технологий. В ходе обучения профессионально ориентированной речи используются традиционные (познавательные 
(когнитивные)), которые базируются на взаимосвязи разных видов языковой деятельности), и инновационные (активные, интерактивные, аудиолингвальные, аудиовизуальные, коммуникативные, творческие), организационные и другие методы.

Таким образом, методика обучения профессионально ориентированной речи иностранных студентов инженерных специальностей охватывает несколько этапов.

Особое внимание заслуживает подготовительный этап. Его целью является подбор актуальных тем, типовых коммуникативных ситуаций, (например, запросить информацию о событии, о характере изучаемых объектов, их признаках, структуре, применении, использовании, функционировании; описать явления, методику исследования и пр.; прокомментировать устройство, предложить иной вариант решения поставленной задачи, сделать вывод (заключение), подвести итог рассуждению и т.д.); определение социально-коммуникативных ролей участников общения; создание тематических словарей профессиональной лексики и подготовка иностранных студентов к исследовательской деятельности. Здесь следует не забывать о существовании в любом научном тексте прагматического плана, при анализе которого нужно учитывать: собственно прагматику текста, т.е. то обязательное свойство всякого текста, которое отражает отношение адресанта к объекту коммуникации, к самому коммуникативному акту и через него к адресату; адресанта и адресата, которые в научном тексте присутствуют опосредованно и совпадают по таким параметрам, как общая научная специальность и принадлежность к одному направлению; прагматическую установку научного текста - убеждение с помощью логического обоснования; прагматическое содержание, включающее цель передачи содержания (коммуникативноинформативную), условия (преимущественно официальную обстановку с установкой на опосредованное общение) и намерение отправителя (передать 
необходимое сообщение кратко, информативно, наглядно); программируемый прагматический эффект, о котором можно судить только по данным обратной связи.

На основе анализа профессиональной речи инженеров выделяют основные темы и соответствующие им типовые коммуникативные ситуации, которые обеспечивают привлечение студентов к профессионально ориентированной коммуникации, например, программная среда - оператор, инженер - машина, техническое задание - исполнитель, инженер системотехник - инженерпрограммист, инженер - вспомогательный персонал, фирма-заказчик инженер.

Наиболее актуальными для профессиональной деятельности будущего инженера определены темы, такие как «Научно-исследовательский институт», «Техническое бюро», «Телекоммуникационные системы и сети», «Тестирование компьютерных программ», «Биомедицинская электроника», «Компьютерно-инженерные технологии в программировании», «Интеллектуальные системы принятия решений» и др.

На этом этапе был разработан спецкурс «Основы информационной терминологии», главная цель которого - обогащение словарного запаса студентов-иностранцев инженерной терминологией и совершенствование уровня владения специальной лексикой русского языка. Содержание спецкурса - состав и семантика инженерной лексики, грамматические и словообразовательные особенности инженерных терминов, орфоэпичные нормы.

Увеличение словарного запаса профессиональными терминами осуществляется на основе использования Поурочного словаря по информатике (русский, украинский, английский, французский, арабский, турецкий, китайский, вьетнамский языки) для студентов-иностранцев (Морозова 2017. 43), созданного в Харьковском национальном университете радиоэлектроники. 
Задача словаря - дать пояснение основных терминов и предложить их перевод, продемонстрировав функционирование наиболее употребительных словосочетаний.

В словарь вошли профессионально ориентированные слова и словосочетания разнотипные по структуре языковые средства, необходимые в различных профессионально языковых ситуациях. Преимуществом словаря являются дидактические принципы наглядности и иллюстрированности: в приложении использованы иллюстрации, таблицы. Для пополнения словарного запаса студентов профессиональной лексикой важен содержательный аспект, который включает презентацию и семантизацию терминоединиц инженерной сферы в рамках обозначенных тем и ситуаций. Основными приемами семантизации были: пояснение значений слов через описание, толкование, подбор синонимов и антонимов, указаний на словообразовательную ценность слова или его внутреннюю форму; использование контекста, перевода или иллюстративного материала, наглядной семантизации, комплексного комментария и др.

Усвоение слова-термина данной специальности начинается с акустического восприятия и проговаривания его слухового образа. Это так называемый этап внешней речи и моторной реализации. Для того чтобы каждый этап в усвоении терминологической лексики проходил с максимальной эффективностью, необходимо «включать» у студентов механизм импринтинга, «когда в памяти образуется как бы ловушка для слова, благодаря чему оно и запечатлевается» (Леонтьев 1983. 126). Таким образом, начальным этапом по формированию у студентов лексико-терминологической основы для построения монологического высказывания является создание мотива и связанной с ним речевой интенции, побуждающих к высказыванию.

Обогащение словарного запаса происходило благодаря прослушиванию фонограмм, просмотру видеофрагментов, работе с дидактическими и справочными материалами. Проводилась работа, направленная на 
активизацию у студентов предыдущих знаний терминологической лексики. Осознание и запоминание студентами лексических единиц на основе усвоения тематическо-функциональных групп помогает выработке умений правильно употреблять слова в соответствии с определенной ситуацией общения. Активизация словарного запаса предусматривает создание системы упражнений на совершенствование лексической компетенции, при этом обучение осуществлялось на уровне слова, словосочетания, предложения, сверхфразового единства.

Студентам были предложены условно-коммуникативные и коммуникативные упражнения, в которые вошли как рецептивнорепродуктивные, рецептивно-продуктивные, так и упражнения творческого характера, которые способствовали активной самостоятельной языковой деятельности на основе моделирования профессионально-коммуникативного поведения в типовых ситуациях профессионально-коммуникативной деятельности. Учебные ситуации создавались на основе профессионально ориентированного, коммуникативно-деятельного, личностно ориентированного и компетентностного подходов. Использование коллективно-групповых форм организации обучения, в том числе подготовка студентов к конференции предусматривали погружение студентов в активную языковую деятельность. Конечным результатом работы на этом этапе было создание самостоятельных высказываний в процессе профессионально ориентированного общения.

Завершающим этапом является овладение иностранными студентами профессионально ориентированным диалогическим говорением разных функциональных типов. Ведущие методы этого этапа: моделирование, профессионально ориентированные ролевые и деловые игры, проблемный, кейс-метод, проблемно-поисковый (беседы, дискуссии), «мозговой штурм», система коммуникативных упражнений. 
Разработанная методика осуществлялась с учетом основ профессиональноязыковой культуры, обеспечения единства психолингвистического, профессионального, духовного, социокультурного и межкультурного аспектов развития профессионально ориентированного говорения иностранных студентов.

Конечным результатом этого этапа стало формирование у студентовиностранцев умений и навыков самостоятельно создавать диалоги (полилоги) разных функциональных типов, регулировать коммуникативное поведение, творчески самореализоваться во время профессионально ориентированного диалогического общения (Пугачев 2016. 87).

В процессе обучения большое внимание уделялось организации самоконтроля студентами собственной устной языковой деятельности, а именно, стимулирование оценочно-контрольных действий в процессе учебноязыковой деятельности. Содержательный аспект включал работу с таблицами само- и взаимооценок, осуществление контроля собственного высказывания и высказываний своих коллег на основе сопоставления выполненных заданий по образцам, исправление ошибок. Конечным результатом было овладение студентами профессионально ориентированным диалогическим говорением, умение контролировать, совершенствовать собственную речь и правильно оценивать речевую деятельность как свою, так и своих коллег.

\section{Заключение}

Таким образом, обучение профессионально ориентированному говорению иностранных студентов инженерных специальностей высших учебных заведений можно преподнести в виде лингводидактической модели, образованной на основе современных требований к профессиональной подготовке, которая отображает цель и содержание образования, очерчивает педагогические условия процесса формирования и конечный результат - 
сформированность профессионально ориентированной диалогической речи у иностранных студентов.

Участие в конференции с сообщением по материалам своей научной работы помогает студенту в дальнейшем, при подготовке к защите дипломной работы.

Предлагаемая нами методика организации и проведения студенческой конференции способствует в ходе подготовки к выступлению совершенствованию иноязычной коммуникативной и межкультурной компетенций студентов в целом, повышает уровень владения иностранным языком. Студенты закрепляют на практике приемы поискового чтения и аудирования, приемы работы с текстом, способы презентации информации. Подготовка монологического высказывания по выбранной теме имеет и общепедагогическую значимость: они начинают понимать, что культурный человек начала XXI в. - это человек, умеющий интерпретировать информацию, и благодаря раскрытым прагматическим пластам текстов находящий общие точки отсчета при обсуждении нового события. Такая работа формирует жизненную и профессиональную позицию будущих инженеров, в докладе студенты отражают не только логику позиций инженеров, но и коммуникативную интенцию авторов публикаций, используемых при подготовке к докладу текстов.

\section{Литература}

1- Вейзе А.А. (1985). Чтение, реферирование и аннотирование иностранного текста. - Москва: Изд-во «Высшая школа».

2- Дроздова И.П. (2009). Ведущุие принциипь профессиональной речи студентов нефилологических спеииальностей средствами украинского языка // Межпредметные связи. - Харков: №15 С.56-62.

3- Клейменова Е.П. (1982). О реферировании как о способе конденсирования научного текста // Вопросы лингвистики и методики преподавания иностранных языков. Выпуск 6 - Москва: Изд-во «Моск. ун-та», С.157-164. 
4- Леонтьев А.А., Китайгородская Г.А. (1983). Содержание и границы понятия «Интенсивное обучение» // Краткосрочное обучение русскому языку иностранцев: Формы и методы. - Москва: Изд-во «Русский язык» С.57-64.

5- Логинова А.В. (2015). Навыки преподавания ХХІ века как условие и показатель качества образовательного прочесса / Молодой ученый. №11 (91) C.72-75.

6- Морозова Л.Ю. (2017). Поурочный словарь по информатике (русский, украинский, английский, франиузский, арабский, турецкий, китайский, вьетнамский языки) для студентов-иностранцев подготовительных факультетов. - Харьков: Изд-во «ХНУРЭ».

7- Образцов П.И. (2005). Проектирование и конструирование профессиональноориентировочной технологии обучения / П.И. Образцов, А.И. Ахулкова, А.Ф. Черниченко. - Орел: Изд-во «ОГУ».

8- Пахалкова-Соич Т.В., Морозова Л.Ю. (2016). Формирование лингвокультурологической компетентности у студентов, изучающих русской язык в условиях билингвизма / Вестник 30. Современный русский язык: функционирование и проблемы преподавания. - Будапешт. С.171-176.

9- Пугачев И.А. (2016). Профессионально ориентированное обучение русскому языку как иностранному: теория, практика, технологии: монография. Москва: Изд-во «РУДН».

10- Смирнова Л.Н. (1978). Реферативный перевод: компрессия на смысловом уровне // Иностранный язык для научных работников. - Киев. С.154-167.

\section{Bibliography}

1- Vejze A.A. (1985). Chtenie, referirovanie i annotirovanie inostrannogo teksta. Moskva: Izd-vo «Vysshaja shkola».

2- Drozdova I.P. (2009). Vedushhie principy professional'noj rechi studentov nefilologicheskih special'nostej sredstvami ukrainskogo jazyka // Mezhpredmetnye svjazi. - Harkov: №15 S.56-62.

3- Klejmenova E.P. (1982). O referirovanii kak o sposobe kondensirovanija nauchnogo teksta // Voprosy lingvistiki i metodiki prepodavanija inostrannyh jazykov. Vypusk 6 - Moskva: Izd-vo «Mosk. un-ta», S.157-164.

4- Leont'ev A.A., Kitajgorodskaja G.A. (1983). Soderzhanie i granicy ponjatija "Intensivnoe obuchenie» // Kratkosrochnoe obuchenie russkomu jazyku inostrancev: Formy i metody. - Moskva: Izd-vo «Russkij jazyk» S.57-64.

5- Loginova A.V. (2015). Navyki prepodavanija XXI veka kak uslovie i pokazatel' kachestva obrazovatel'nogo processa / Molodoj uchenyj. №11 (91) S.72-75.

6- Morozova L.Ju. (2017). Pourochnyj slovar' po informatike (russkij, ukrainskij, anglijskij, francuzskij, arabskij, tureckij, kitajskij, v'etnamskij jazyki) dlja studentovinostrancev podgotovitel'nyh fakul'tetov. - Har'kov: Izd-vo «HNURJe». 
7- Obrazcov P.I. (2005). Proektirovanie $i$ konstruirovanie professional'noorientirovochnoj tehnologii obuchenija / P.I. Obrazcov, A.I. Ahulkova, A.F. Chernichenko. - Orel: Izd-vo «OGU».

8- Pahalkova-Soich T.V., Morozova L.Ju. (2016). Formirovanie lingvokul'turologicheskoj kompetentnosti u studentov, izuchajushhih russkoj jazyk $v$ uslovijah bilingvizma / Vestnik 30. Sovremennyj russkij jazyk: funkcionirovanie i problemy prepodavanija. Budapesht. S.171-176.

9- Pugachev I.A. (2016). Professional'no orientirovannoe obuchenie russkomu jazyku kak inostrannomu: teorija, praktika, tehnologii: monografija. - Moskva: Izd-vo «RUDN».

10- Smirnova L.N. (1978). Referativnyj perevod: kompressija na smyslovom urovne // Inostrannyj jazyk dlja nauchny rabotnikov. - Kiev. S.154-167.

\section{HOW TO CITE THIS ARTICLE}

Пахалкова-Соич Т. В. \& Морозова Л. Ю. (2020). Professionally-Oriented Linguvodidactics: Formation of Research Competence of Students Who Learn Russian. Issledovatel'skiy Zhurnal Russkogo Yazyka I Literatury, 8(1), 83-102.

DOI: $10.29252 /$ iarll.15.83

URL: http://www.journaliarll.ir/index.php/iarll/article/view/110

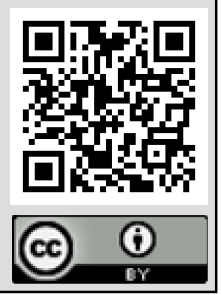




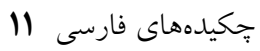

\title{
روشهاى آموزش زبان با تكيه بر حرفه و تخصص زبانآموزان:
}

\section{ايجاد مهارتهاى يزؤهشى در دانشجويان رشتهُ زبان روسى}

\author{
تاتيانا ولاديميروونا باخالكووا-سائيج' دائيج

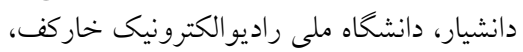

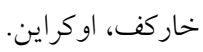

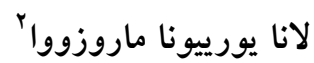

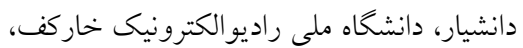

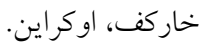 \\ (تاريخ دريافت: آوريل 19.r؛ تاريخ بذيرش: سيتامبر 19.19)
}

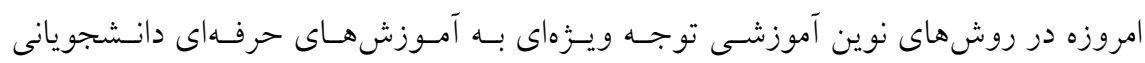

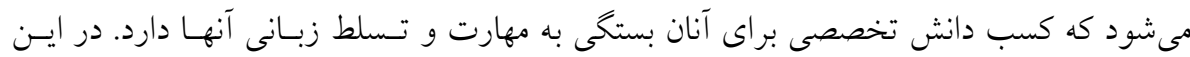

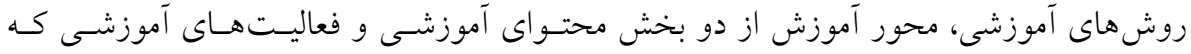

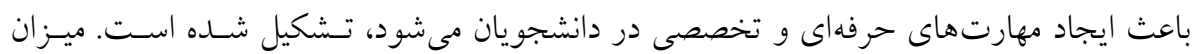

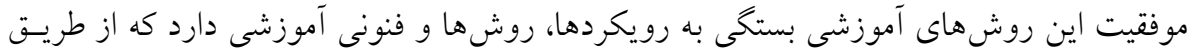

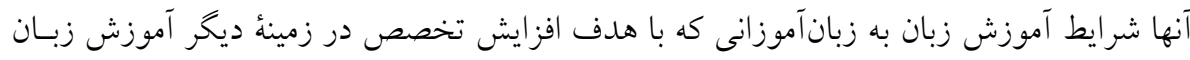

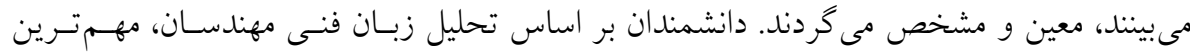

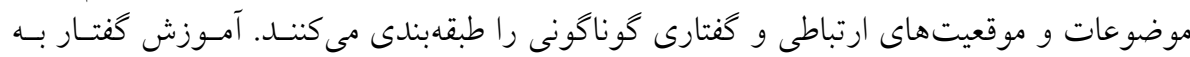

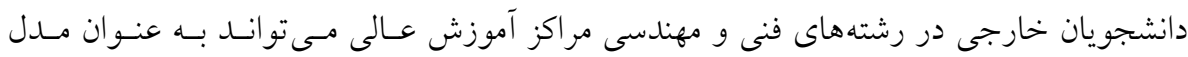

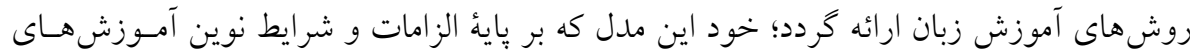

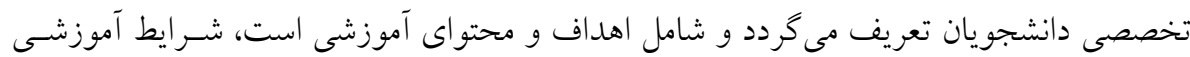

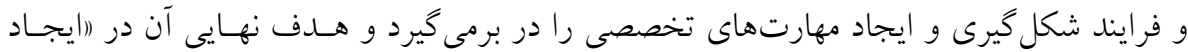

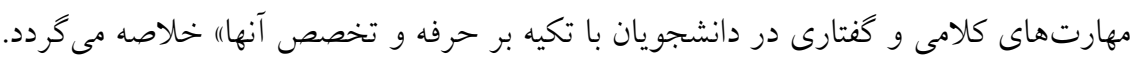

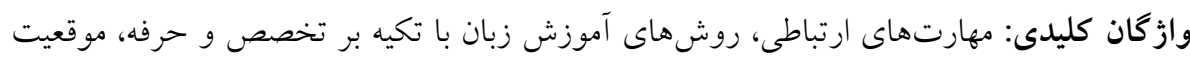

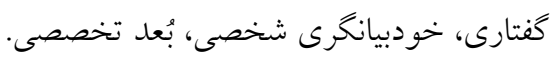

1. E-mail: p-soich@rambler.ru

2. E-mail: lanmoroz@rambler.ru 